\title{
Show-stopping innovations at Voco - the dentist's partner!
}

\author{
As the demand for minimally invasive, durable, restorative solutions continues to rise, today's clinicians require \\ manufacturers to listen, innovate and respond. BDIA Dental Showcase exhibitors Voco give us an insight into the high- \\ quality products they'll be displaying to help deliver the performance and aesthetics that today's patients demand.
}

For over 30 years, Voco has been one of the leading international manufacturers of dental materials, particularly in the fields of preventive, restorative and minimally invasive dentistry. The company supplies products to over 100 countries, and clinicians from around the world have come to rely on the high quality and innovative functionality of their wide portfolio of products.

All Voco's products are developed and made in their state-of-the-art laboratories and production facilities in Cuxhaven. Quality also derives from intensive testing and stringent quality control measures, an area that Voco has fully invested in with their certified quality management system, in which all stages of development and manufacturing are subject to strict monitoring. As a result, Voco ensures high safety and quality standards and confers the 'Made in Germany' seal of approval.

\section{Quality-assured and award-winning} As a leader in nano-technology, Voco's products have received high praise and recognition internationally, including several five-star ratings from independent US testing institute, The Dental Advisor, including their 'Editors' Choice' award for Admira Fusion Flow. This is the flowable version of the first purely ceramic-based, light-curing, radiopaque, Admira Fusion, which was the world's first dental restorative material to use this unique

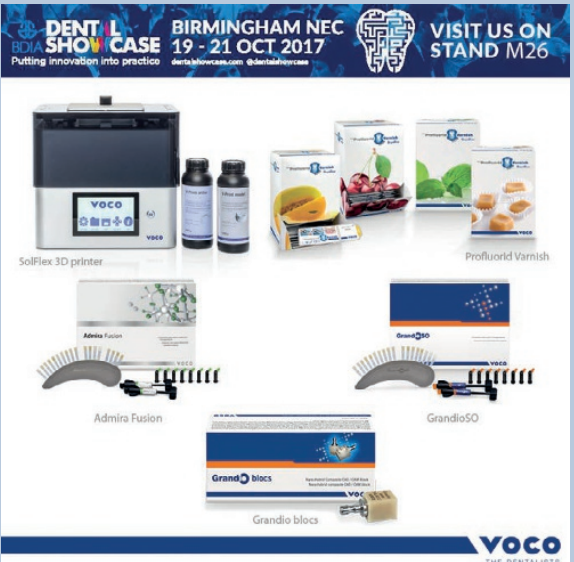

'Pure Silicate Technology' with its remarkably low polymerisation shrinkage ( $1.25 \%$ by volume) and shrinkage stress.

Voco researchers are in close contact with more than 150 universities and research institutes worldwide and have been leading several research projects co-sponsored by the German Federal Ministry of Research. Their most notable development is in combining proven nanohybrid and ORMOCER (Organically Modified Ceramics) technology, which have revolutionised the dental composite market with their high performance in shrinkage, biocompatibility and aesthetics, to form the base of Voco's popular Admira range. The light-curing and radiopaque Admira Fusion delivers a highly biocompatible material for anterior and posterior use. With $84 \%$ (by weight) inorganic filler content, which delivers outstanding handling in comparison with all market-relevant restorative composites, it exhibits by far the lowest level of polymerisation shrinkage ( $1.25 \%$ by volume) as well as extremely low shrinkage stress.

\section{Furthering your education}

Voco sees itself as the dentist's partner, not only through the quality of their products, but also through constant communication and conversation with dental clinicians from around the world. Their 'International Fellowship Symposium' series of events hosts discussions about current issues and the latest methods in dentistry with industry professionals.

As a result, they are constantly extending their network of contacts and gaining inspiration from practising clinicians, which informs everything they do. Armed with considerable in-practice experience and knowledge, Voco listen to their opinions and needs, feeding this back into the company so that they truly work in partnership with the industry.

Voco's commitment to continuing education over the years has resulted in a varied programme of educational events, backed up with education resources, including online learning courses, a multimedia training library and free access to previously-recorded webinars.

\section{Showcase innovations}

VOCO would like to invite all clinicians to BDIA Dental Showcase, Stand M26, at the NEC, Birmingham, from 19-21 October. Here they will be able to meet their knowledgeable team of experts who will be on hand to offer advice on all aspects of restorative, preventive and minimally invasive dentistry and experience their products first-hand.

Visitors to the stand will also discover VOCO's NEW Grandio blocs, guaranteeing outstanding aesthetic results and meeting the highest demands of same-day chairside CAD/ CAM restorations. Grandio blocs are the strongest in their class, with a superior biaxial flexural material strength of $333 \mathrm{MPa}$ and the highest filler content of any bloc on the market today at $86 \%$.

There'll be a few VOCO favourites on-stand too, including the renowned Admira Fusion, offering excellent handling and high surface hardness to guarantee first-class, long-term results, and Profluorid Varnish, which contains $5 \%$ sodium fluoride $(22,600 \mathrm{ppm}$ fluoride) to protect teeth against acid attack, promote remineralisation and contribute to the formation of fluorapatite. Plus, with dentistry rapidly moving into the digital realm, VOCO are excited to be introducing their SolFlex 3D printer range, which allows users to benefit from the efficiency, accuracy and predictability of digital designs throughout the production stage.

Voco strives to help the worldwide dental industry and become a valuable partner for today's clinicians. They recognise that the more people that join the conversation, the better they will become at developing the products with the right qualities.

Visit VOCO on Stand M26. Call 0080044 444555 or email service@VOCO.de 